\title{
LOS VERBOS PSICOLÓGICOS EN \\ LOS MANUALES DE ELE: UN ANÁLISIS COMUNICATIVO-COGNITIVO ${ }^{1}$
}

\author{
PSYCH-VERBS IN ELE TEXTBOOKS: A \\ COMMUNICATIVE-AND-COGNITIVE-BASED ANALYSIS
}

\author{
BEATRIZ MARTÍN-GASCÓN \\ Universidad de Córdoba, España \\ Z82magab@uco.es
}

\section{RESUMEN}

Las Gramáticas Cognitiva y Operativa como enfoques centrados en la enseñanza de lenguas defienden el imperturbable vínculo forma-significado y le confieren así a la gramática el valor semántico que merece. Sin embargo, su aplicación en el aula de Español Lengua Extranjera (ELE) no ha visto explotado todo su potencial. En este sentido, resulta útil abordar las dificultades que presentan los aprendientes de ELE en la correcta asimilación de cláusulas Experimentador-Objeto con verbos psicológicos. A esta complicación se suma el enfoque tradicional y descriptivo adoptado en los manuales. Por ello, este estudio busca examinar desde la perspectiva de estos enfoques el tratamiento de estas estructuras en 10 manuales de gran impacto correspondientes a los niveles A1, A2 y B1 (sumando así un total de 36 manuales y 70 unidades) y estudiar cómo se ajustan al inventario de emociones del Plan Curricular del Instituto Cervantes (PCIC). Los resultados corroboran la hipótesis de que los verbos psicológicos se presentan escasa y asistemáticamente en el PCIC y en los manuales, y evidencian cierta disparidad entre los contenidos por niveles que el PCIC detalla. Partiendo de las limitaciones presentes en los manuales, se propone la base de un material que incorpora el modelo operacional y los roles semántico-referenciales de Experimentador y Estímulo.

Palabras clave: Gramática Cognitiva, cláusulas Experimentador-Objeto, manuales de ELE.

${ }^{1}$ Esta investigación se circunscribe en el marco del apoyo pre-doctoral FPU del Gobierno de España, Ministerio de Ciencia e Innovación. No FPU17/04542 


\section{ABSTRACT}

Cognitive and Operative Grammars as language teaching approaches advocate the unbreakable link of form-meaning, thus recognizing the semantic contribution offered by every grammatical element. Still, its application in the Spanish as a Foreign Language (ELE in the native language acronym) classroom has not yet been fully exploited. In this respect, it is useful to address the difficulties that arise when ELE learners acquire Experiencer-Object clauses with psych-verbs. An additional obstacle to the matter lies in the traditional and descriptive approaches followed by textbooks. Therefore, the study aims at exploring these expressions from the perspective of the above-mentioned approaches in 10 of the best-sold textbooks on the market (levels A1, A2 and B1, resulting in a total of 36 textbooks and 70 units) and at examining how they adjust to the emotion inventory of the Curricular Plan of the Instituto Cervantes (CPIC). Results corroborate the hypothesis regarding the poor and unsystematic treatment of psych-verbs in the CPIC and textbooks and show how these latter depart to a great extent from the $C P I C$ with regard to the contents assigned to each level. Considering the limitations observed in the textbooks, we propose the basis of an operative didactic material that incorporates the semanticreferential roles of Experiencer and Stimulus.

Keywords: Cognitive Grammar, Experiencer-Object clauses, ELE textbooks.

Recibido: 28/04/2020. Aceptado: 09/10/2020.

\section{INTRODUCCIÓN: EL COMPONENTE COGNITIVO EN LAS CLÁU- SULAS DE VERBOS DE AFECCIÓN}

T a Lingüística Cognitiva (LC) es un enfoque de estudio del lenguaje que ceny los concibe como creadores de la lengua. El hablante, influido por su experiencia perceptiva y emocional elige deliberadamente de entre las formas lingüísticas proporcionadas por su lengua aquellas que le permiten mantenerse fiel a su intención comunicativa. Así, la manera en que percibe e interpreta el complejo mundo que lo rodea (es decir, su representación mental) i.e., el dominio de las emociones repercute, por ejemplo, en el uso de unos verbos psicológicos u otros (representación lingüística). Este tipo de verbos (i.e., me apasiona, detesto, etc.,) pertenecen a una categoría más general, denominada 'psych-verbs', que expresa eventos de proceso mental y que recoge los verbos de sensación física, emoción, cognición, volición y percepción (Miglio, Gries, Harris, Wheeler, Santana-Paixão, 2013; Verhoeven, 2007) ${ }^{2}$. Esta asociación entre pensamiento y lenguaje implica

${ }^{2}$ Para el presente estudio, nos referiremos a los verbos de emoción como verbos psicológicos o de afección indistintamente. 
la existencia de valores prototípicos de los elementos gramaticales, lo que, en el ámbito de la adquisición de lenguas extranjeras, y más en concreto del Español como Lengua Extranjera (ELE), se traduce en que el estudiante cuenta con las herramientas necesarias para combinarlos y así asimilar su significado gramatical. Si el docente de ELE dirige la atención del aprendiente hacia el contraste de significados y el valor unívoco de los aspectos gramaticales más dificultosos, esto es, cómo cada forma crea una imagen mental distinta, este le facilitará una comprensión más profunda de cómo se estructura el mundo en la lengua meta (para una bibliografía actualizada sobre LC y enseñanza de ELE, véase Ibarretxe Antuñano, Cadierno-López y Castañeda-Castro, 2019). Obsérvense, por ejemplo, el concepto prototípico de 'declaración (indicativo) - no declaración (subjuntivo)' puramente de la Gramática Cognitiva (GC) que define al modo verbal en español (Ruiz Campillo, 2007) o la sistematicidad didáctica en cuanto a la explicitación de criterios unificadores a la hora de organizar el qué enseñar y en qué nivel (i.e., la clasificación de emociones según su connotación que ofrece este estudio evidencia esta sistematicidad, puesto que permitirá posteriormente desarrollarlas por nivel de dominio y extenderlas desde niveles básicos hasta niveles avanzados de aprendizaje de lenguas extranjeras - LEs).

En relación con esta búsqueda del valor único y permanente de una forma y el objetivo final de querer significar, destaca la Gramática Operativa (GO) (Ruiz Campillo, 2007), un acercamiento cognitivo y operativo a la gramática basado en la reducción de los valores gramaticales a un significado permanente. Se trata, por tanto, de un enfoque centrado en la enseñanza de formas y en la intención comunicativa del hablante que se sitúa dentro del marco de la LC y la GC. Así, la GO es una gramática significativa que proporciona las herramientas necesarias al aprendiente para que este exprese sus emociones de manera competente. A este respecto, las investigaciones cognitivas de Talmy (2000), y particularmente la noción de 'valencia' en relación con los verbos de afecto, han aportado luz a la conceptualización de la emoción. En el caso del español, los verbos que expresan emociones, sensaciones físicas y estados de ánimo que codifican al experimentador como objeto son más frecuentes que en otras lenguas indoeuropeas o indoiranias ${ }^{3}$. Este tipo de construcciones 'inversas', que muestran al experimentador como una entidad receptora de energía psíquica cuyo estado es consecuencia del efecto de un

\footnotetext{
${ }^{3}$ Obsérvense los siguientes ejemplos contrastados con hablantes nativos:

(1) Español: Tengo miedo a las arañas (-) / Me dan miedo las arañas (+)

(2) Portugués: Tenho medo de aranhas (+)

(3) Francés: J’ai peur des araignées $(+)$

(4) Alemán: Ich habe Angst vor Spinnen (+)

(5) Inglés: I fear/ am scared of spiders (+) / Spiders frighten/scare me (-)

(6) Neerlandés: Ik ben bang voor spinnen (+) / Spinnen maken mij bang (-)

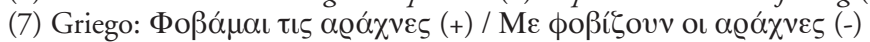

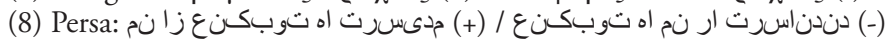


estímulo externo, resultan dificultosas para los aprendices de ELE en contextos de instrucción donde el input es escaso ${ }^{4}$. Como consecuencia, el estudiante fosiliza inconscientemente aspectos léxico-gramaticales propios de su lengua materna. No obstante, esto dependerá, en parte, de las reflexiones que se lleven a cabo en el aula y de la correcta explotación de las posibilidades ofrecidas por la GC. Por otro lado, en las estructuras que lo subjetivizan, el efecto surge intrínseca y libremente (Talmy, 2000). Al describir una situación afectiva, este autor subraya las diferencias lexicales en los verbos de afecto que son motivadas por los diferentes roles semántico-referenciales en un episodio determinado y cuyo uso varía según el foco de atención, i.e. si el aspecto saliente son las cualidades del estímulo (Figura 1) o si es el estado del experimentador (Figura 2$)^{5}$.

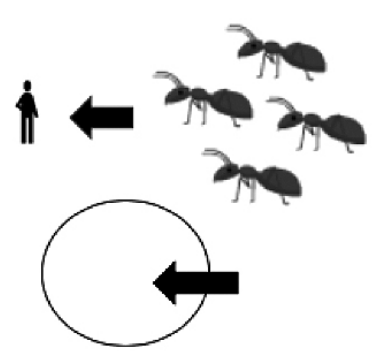

Figura 1. Me dan miedo las hormigas.

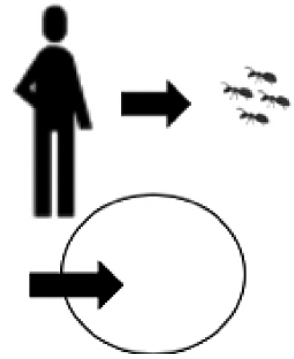

Figura 2. Tengo miedo a las hormigas.

Siguiendo la definición de 'emoción' que proponen Mulligan y Scherer (2012), válida en un marco cognitivo, las representaciones lingüísticas objeto de estudio designan episodios mentales deliberados que experimenta el sujeto a través de los sentidos y la memoria, y que duran un tiempo relativamente corto. El objeto de estos episodios afectivos puede ser "externo o interno, real o ficticio, concreto o abstracto" (Mulligan y Reiner, 2012, p. 348). Es la intencionalidad de dichos episodios perceptuales la que explica el carácter intencional de las emociones. Así, cuando el hablante afirma 'me molestan los petardos', su aversión recae en el estímulo externo, ficticio y abstracto que son los petardos que parece escuchar o que recuerda por experiencia. Estudios como el de Kleinginna y Kleinginna (1981), en búsqueda de una definición consensuada de las emociones, las categorizan con base en los fenómenos emocionales o los aspectos teóricos enfatizados en su conceptualización. Los autores abogan por una definición formal que permita diferenciar las emociones de otros procesos psicológicos. Arguyen que la emoción es "un complejo conjunto de interacciones entre factores subjetivos y objetivos me-

\footnotetext{
${ }^{4}$ Tanto el experimentador como el estímulo son elementos conceptuales de nuestra experiencia.

${ }^{5}$ Ejemplos de elaboración propia.
} 
diados por sistemas neuronales y hormonales" (p. 355) que pueden (a) dar lugar a experiencias afectivas, (b) generar procesos cognitivos, como efectos perceptuales con alto impacto emocional, (c) activar ajustes fisiológicos, y (d) llevar a comportamientos comúnmente expresivos, con objetivos específicos y adaptativos. Así, aunque el debate sobre este constructo y su diferenciación frente a otros episodios perceptuales, como los sentimientos o los estados de ánimo, ha sido y continúa siendo objeto de estudio en diferentes disciplinas (en la actualidad destacan las investigaciones de grupos interdisciplinares como LEIDE, 2017, de la Universidad de Alcalá; o CISA, 2013, de la Universidad de Ginebra), para los propósitos de esta investigación nos referiremos a estos episodios de relativa corta duración como emociones, siguiendo las definiciones de los autores anteriormente citados.

Pese a los grandes avances en la teoría cognitiva, la enseñanza de ELE y, sobre todo, el diseño de materiales, siguen mostrándose algo reacios a abrirle las puertas a la enseñanza explícita de significados gramaticales en términos cognitivos y operacionales, tal y como el análisis de manuales aquí presentado pondrá de manifiesto. Si bien la LC ha sido y sigue siendo muy estudiada desde una perspectiva teórica, todavía adolece de un número parejo de estudios empíricos que permitan establecer un punto de unión entre teoría y práctica. Por otro lado, aunque se trata de un enfoque basado en el uso de la lengua, su aplicación todavía carece del diseño normalizado de materiales didácticos en contextos de instrucción de LEs, sobre todo del español. No obstante, en los últimos años se ha presenciado una mayor proliferación de investigaciones centradas en la aplicación del modelo cognitivo a la enseñanza-aprendizaje de ELE. A este respecto, destaca el volumen recientemente editado por Ibarretxe Antuñano et al. (2019), donde se incluyen estudios que versan sobre propuestas descriptivas y datos empíricos con pautas para ayudar a instructores a integrar la LC en el aula. Así, es fundamental sumarse a estas propuestas, trasladar los resultados de estas y de futuras investigaciones al aula de ELE, reformular el tipo de material al que está expuesto el aprendiente y no limitarse a la postulación de principios teóricos. En esta línea, la idea que presenta Llopis García (2018) al referirse a la LC como ejercicio pedagógico integrador de estilos de aprendizaje basados en la comprensión holística y el conocimiento experiencial se suma a la regeneración de la didáctica de ELE predominante y al distanciamiento del aprendizaje lineal marcado por las unidades de los manuales.

Para que se produzca dicho cambio radical en la enseñanza de ELE es necesaria la creación de materiales didácticos centrados en potenciar la asimilación significativa y lógica de las representaciones lingüísticas en esta lengua. Igualmente, el diseño de materiales debe complementarse con una formación y reflexión en la formación de los docentes de ELE. De esta manera, el docente se alejará de la gramática taxidérmica y discursivista, y el aprendiente será consciente del qué, del porqué y del para qué, y podrá improvisar y crear su propia comunicación. El paso previo al diseño y aplicación de un material de corte cognitivo es el análisis meto- 
dológico exhaustivo de los manuales actuales de ELE, así como del Plan Curricular del Instituto Cervantes (PCIC), documento de referencia para docentes de ELE. Este análisis es la clave que nos permitirá abrir las puertas a futuras contribuciones empíricas para así enriquecer la enseñanza-aprendizaje del español.

Asimismo, aunque la expresión de la emoción ha sido objeto de estudio en diversas lenguas (Barcelona y Soriano, 2004; Dewaele, 2018; Ivaz, Costa y Duñabeitia, 2016; Kövecses, 2000; Molinaro, 2020; Ogarkova, Soriano y Gladkova, 2018; Soriano, 2016) y la alternancia en estructuras de Experimentador Sujeto (ES) (i.e., adoro) y Experimentador Objeto (EO) (i.e., me encanta) se ha investigado en el ámbito de la psicolingüística, la adquisición y el análisis de corpus (Hartshorne, Pogue y Snedeker, 2015; Melis, 1999; Miglio et al., 2013; Vázquez Rozas, 2012)6, salvo omisión involuntaria, todavía no se ha llevado a cabo ninguna investigación exhaustiva sobre su tratamiento en los manuales de ELE de mayor difusión, medio didáctico al que más expuestos están los aprendientes durante su proceso de aprendizaje en contextos de instrucción. Por este motivo, el presente estudio tiene como objeto explorar y tomar conciencia de la manera en la que las editoriales de mayor impacto por su presencia en el mundo de ELE tratan las expresiones de verbos psicológicos en español. Para ello planteamos dos hipótesis: por un lado, nuestra experiencia docente nos lleva a presuponer que ningún manual del mercado actual trabaja suficientemente los verbos psicológicos o de afección desde niveles iniciales de aprendizaje-enseñanza de ELE; y, por otro, pronosticamos que no se abordan las expresiones meta desde un modelo cognitivo y operacional, ignorando así que todo fenómeno léxico-sintáctico posee una motivación semántico-conceptual ${ }^{7}$.

Dicho esto, las preguntas de investigación (PIs) que guiarán el estudio son las siguientes: (PI1) ¿Cómo se clasifica la expresión de la emoción en el inventario del PCIC?; (PI2) ¿Qué expresiones lingüísticas aparecen en el PCIC para cada emoción y cómo se presentan por niveles (A1-B2)?; y (PI3) ¿Cómo tratan los manuales de ELE de mayor difusión la expresión de la emoción a través de los verbos de afección? (PI3.1) ¿¿Se ajustan al PCIC? (PI3.2) ¿La trabajan desde un modelo de corte cognitivo y operacional? Para dar respuesta a estas PIs, se analizará, en primer lugar, el inventario de emociones del Plan del Instituto Cervantes (PCIC),

${ }^{6}$ Hartshorne et al. (2015) exploran la variabilidad en estas estructuras y cómo esta aparente inconsistencia es el resultado de las diferencias en la representación léxico-semántica de este tipo de verbos. Melis (1999) analiza una muestra de un total de 839 cláusulas SO con verbos causativos emocionales extraída de textos mexicanos de finales del siglo XX. En su estudio multifactorial, Miglio et al. (2013) trabajan a partir de parte del corpus analizado por Vázquez Rozas (2006) y del Corpus de Español de Davies (2002) un total de 1.656 casos. Vázquez Rozas (2012) examina el uso de los roles semántico-referenciales de construcciones SE y SO a partir del corpus ARTHUS, a través de la base de datos ADESSE.

${ }^{7}$ Considerando los dos tipos de expresiones objeto de estudio (ES y EO) y de acuerdo con el principio cognitivo de no-sinonimia (Goldberg, 1995), "si dos construcciones son sintácticamente diferentes, estas deben ser semántica o pragmáticamente distintas" (p. 67). 
vademécum en la enseñanza de ELE. Posteriormente, se centrará la atención en cómo los 10 manuales seleccionados en cada uno de los niveles analizados, desde el A1 hasta el B1 (sumando así un total de 36 manuales examinados) se ajustan al $P C I C$ y se explorará hasta qué punto incorporan el componente cognitivo. Finalmente, se propone el diseño de un material didáctico de corte cognitivo que parta de las limitaciones de los manuales y que se base en los roles de experimentador y estímulo. Este estudio es un primer paso hacia la regeneración de la didáctica de ELE imperante y hacia un distanciamiento del aprendizaje lineal marcado por las unidades de los libros de texto.

\section{METODOLOGÍA}

El análisis del corpus seleccionado se basa en la tradición metodológica de la lingüística aplicada de corte cognitivo, puesto que se trata de un estudio exploratorio-cuantitativo-interpretativo (paradigma mixto propugnado por Grotjahn, 1987). La razón que subyace a la elección de dicho método es la unificación de diversas metodologías de investigación que proporcionen un entendimiento más profundo sobre la inclusión de estas estructuras problemáticas por su naturaleza en el $P C I C^{8}$. Así, mediante un método no experimental, se recogieron datos de naturaleza cualitativa extraídos del inventario de elementos léxicos de los manuales. Estos se sometieron a un simple análisis estadístico con vistas a medir los resultados de forma objetiva. A continuación, se llevó a cabo un análisis interpretativo.

\subsection{Técnicas de recogida de datos}

Para la recogida puramente cuantitativa de datos se empleó una hoja de cálculo de Excel donde se incluyeron los resultados codificados del análisis de las expresiones meta del PCIC y de los manuales más actuales existentes en el mercado de ELE. Asimismo, se diseñó una plantilla por unidad para la recogida de información tanto cualitativa como cuantitativa sobre el número de expresiones de cada emoción (el 'tipo': el deseo, y la frecuencia o 'caso': "quiero", "me gustaría”, etc.,), el contexto en que aparecen (i.e., durante la explicación del ejercicio, el cuerpo, la sistematización puramente gramatical y/o la producción) y su función comunicativa (ver Anexos 1 y 2$)^{9}$.

\footnotetext{
${ }^{8}$ Resulta necesario enfatizar que el estudio aborda unas estructuras léxicas específicas de expresión de la emoción: los verbos psicológicos que poseen carga emocional y no toda la casuística de expresiones de afección (i.e., 'Eres la mejor).

${ }^{9}$ Los Anexos se encuentran disponibles en la plataforma de libre acceso Open Science Framework (Center for Open Science, 2013), en la siguiente dirección: https://osf.io/6kdw4/quickfiles.
} 
A partir de los datos obtenidos y anotados por unidad, se creó una segunda plantilla para cada manual (Anexo 3) para elaborar un informe detallado del tratamiento de las estructuras meta según 20 criterios comunicativos y cognitivos (Tabla I) inspirados en diversas fuentes (Bielak y Pawlak, 2013; Newby, 2012). De esta manera, a partir de los indicadores especificados, se buscaba concluir sobre el posicionamiento teórico adoptado por los manuales estudiados respecto al uso de las estructuras objeto de estudio para la expresión de la emoción. Se pretende que estas técnicas de trabajo desarrolladas (i.e., las plantillas) sirvan de instrumento de análisis para futuras investigaciones.

Tabla I. Criterios comunicativos y cognitivos.

1. Estructura el aprendizaje del elemento lingüístico en torno a 4 fases: concienciación lingüística, conceptualización y formulación de hipótesis, procedimentalización del conocimiento y actuación lingüística en tiempo real

2. Aprendizaje por tareas

3. Imposición de la reflexión explícita durante la presentación, la realización (la corrección) y (la discusión)

4. Profundidad del procesamiento

5. Elementos gramaticales significativos

6. Gramática motivada por la semántica subyacente

7. Factores pragmáticos y discursivos incluidos en el cambio de significado de los elementos

8. Descripción y sistematización de recursos gramaticales

9. Análisis semántico detallado del elemento gramatical

10. Valor conceptual otorgado

11. Existencia de un metalenguaje claro y accesible

12. Integración de ilustraciones pictóricas acompañando la descripción de la expresión meta

13. Filtro de implicación

14. Integración interpersonal y social

15. Personalización

16. Incorporación del factor lúdico y humor

17. Desafío

18. Léxico sencillo

19. Uso verosimil de la lengua meta: autenticidad del proceso comunicativo

20. Evaluación vs. Aprendizaje 


\subsection{Procedimiento y corpus seleccionado}

Previo al análisis exploratorio de manuales, las emociones y sus correspondientes expresiones lingüísticas contenidas en el PCIC fueron estudiadas y categorizadas por dos expertos lingüistas. El PCIC, que se encuentra disponible en la página web del Centro Virtual Cervantes (Instituto Cervantes, 2006), es un documento de consulta obligatoria tanto para autores de manuales como docentes de ELE. Se trata de una obra muy reputada porque incluye las distintas variedades del español y desarrolla detalladamente sus inventarios de especificaciones. Conforme al MCERL (Marco Común Europeo de Referencia para las Lenguas), estándar internacional que define la competencia lingüística en una escala de niveles desde un A1 hasta un C2, el PCIC fija los Niveles de Referencia (Consejo de Europa, 2002) y establece los contenidos a partir de unos objetivos organizados en torno a las tres dimensiones del alumno: la de hablante intercultural, la de agente social y la de aprendiente autónomo. Así, los contenidos integrados en el inventario del PCIC sirvieron de referencia para el análisis del corpus seleccionado ${ }^{10}$. En cuanto a las referencias a la expresión de la emoción, en la actualización más reciente del documento europeo incluida en el Companion Volume (Consejo de Europa, 2017), aunque desde un nivel A1 se espera que el alumno sea capaz de utilizar palabras y frases simples para expresar cómo se siente, es, sobre todo, a partir del nivel B1 donde las emociones adquieren relevancia. Otros referenciales, como el MAREP (Consejo de Europa, 2004), que sigue un enfoque plural de variedades lingüísticas y culturales, destaca, asimismo, la importancia de conocer las diferencias en la expresión verbal de los sentimientos y emociones en las distintas lenguas, aunque no detalla un nivel específico.

La muestra de manuales analizada se compuso de 10 libros de texto para adultos correspondientes a los niveles A1, A2 y B1 del MCERL procedentes de editoriales importantes (i.e., Difusión, Anaya) en este ámbito (ver Anexo 4: editoriales, manuales, niveles, autores y año de edición) ${ }^{11}$. En la selección del corpus se

${ }^{10}$ Puesto que el PCIC presenta los inventarios por bloques A1-A2 y B1-B2 y presuponemos que la mayor riqueza de verbos de emoción se encuentra en este último nivel, para el análisis del PCIC hemos contemplado expresiones hasta el nivel B2 como punto de partida. No obstante, este nivel no se ha explorado en los manuales, ya que partimos de la base de que es fundamental incorporar el estudio de la expresión de la emoción desde niveles básicos.

${ }^{11}$ Gente Hoy (Martín Peris y Baulenas, 2013, 2014); Campus Sur (Rosales Varo et al., 2017); Bitácora (Sans Baulenas, Martín Peris, Garmendia, Conejo, 2018); Aula Internacional (Corpas, García, Garmendia, Sans Baulenas, 2013, 2014); GBE (Alonso Raya et al., 2011); Nuevo Prisma (Equipo Nuevo Prisma, 2012, 2014, 2015); Etapas (De Dios Martín y Eusebio Hermina, 2012; De Dios Martín, Menéndez y Eusebio Hermina, 2010; Equipo Entinema, 2009a, 2009b, 2009c, 2010a, 2010b, 2010c, 2010d, 2010e, 2010f); ¡Genial! (García Sánchez, Mena Octavio, Méndez Santos, Tudela Capdevila, Cruz Moya, 2018; Herrero Fernández, Martínez-Delgado Veiga, Planelles Almeida, Torrado Solo de Zaldívar, Cruz Moya, 2017); AgenciaELE (Fernández et al., 2018; Gil et al., 2017); 
consideraron aspectos como la variedad de enfoques (cognitivo, léxico, por tareas y nocio-funcional, principalmente), la actualidad de sus últimas ediciones y su presencia en el aula de ELE en enseñanza reglada y no reglada (i.e, en instituciones como el Instituto Cervantes). Los procedimientos utilizados para la identificación de las expresiones lingüísticas objeto de estudio en las diferentes unidades fueron: el poder ilustrativo del título de la unidad (i.e., ‘Ay ¡Qué dolor!', 'Nos gustó mucho'...), la temática con la que suelen aparecer (enfermedades, gastronomía, etc.,), los contenidos funcionales (expresar sentimientos y emociones) y léxicogramaticales (el verbo "gustar") y palabras clave como 'construcciones valorativas', 'sentimiento', etc. La validez de dichos procedimientos (i.e., selección de manuales y fases de análisis) fue testada mediante la revisión de un segundo especialista del ámbito de ELE. Aunque somos conscientes de que los verbos psicológicos pueden aparecer en textos y actividades de unidades que no abordan explícitamente este tema, consideramos que el total de 36 manuales y 70 unidades observadas (Anexo 5: unidades seleccionadas de cada manual) constituyen una muestra considerablemente amplia para extraer resultados ilustrativos del panorama contemporáneo del tratamiento de estas estructuras en manuales de ELE.

\section{ANÁLISIS E INTERPRETACIÓN}

\section{1. (PI 1) ¿Cómo se clasifica la expresión de la emoción en el inventario del PCIC?}

Las estructuras que el $P C I C$ recoge para la expresión de la emoción a través de verbos de afección aparecen por primera vez en la sección Gramática, apartado 12: El sintagma verbal, descritos como verbos psicológicos de emoción psíquica y física. En el caso del nivel A1, se presenta el verbo gustar y en el nivel A2, los verbos encantar y doler. Asimismo, en la sección Gramática, en el apartado 15: Oraciones compuestas por subordinación del nivel B1, las oraciones subordinadas sustantivas los introducen: 'Me da miedo hablar', 'Me encanta que me llames' y 'Me encanta ir al cine'. Es, sin embargo, en el apartado 3. Expresar gustos, deseos y sentimientos de la sección Funciones donde se incluyen las expresiones meta repartidas en el inventario de los diferentes niveles (Tabla II). La mayoría de los subapartados trabajan la expresión de estas (i.e., preferencia: 'Prefiero que empieces tü), aunque hay algunos que ponen el énfasis en la pregunta (i.e., preferencia: ‘'Prefieres que vaya yo?').

Método (Cárdenas Bernal, Hierro Montosa, Robles Ávila, Peláez Santamaría, 2018a, 2018b; Esteba Ramos et al., 2017). Se trabajó con las ediciones digitales cuando fue posible. 
Tabla II. División de subapartados del PCIC en "expresar" y "preguntar por".

\begin{tabular}{ll}
\hline & 3.2. gustos e intereses, 3.3. aversión, 3.5. preferencia, 3.6. indiferencia \\
& o ausencia de preferencia, 3.8. deseos, 3.10. planes e intenciones, \\
& 3.10.1. planes e intenciones frustrados, 3.12. alegría y satisfacción, \\
3.13. tristeza y aflicción, 3.14. placer y diversión, 3.15. aburrimiento, & 3.76. hartazgo, 3.17. enfado e indignación, 3.18. miedo, ansiedad y \\
preocupación, 3.19. nerviosismo, 3.20. empatía, 3.21. alivio, 3.22. & esperanza, 3.23. decepción, 3.24. resignación, 3.25. arrepentimiento, \\
& $\begin{array}{l}\text { 3.26. vergüenza, 3.27. sorpresa y extrañeza, 3.28. admiración y } \\
\text { orgullo, 3.29. afecto, 3.30. sensaciones físicas }\end{array}$ \\
\hline Preguntar por & $\begin{array}{l}\text { 3.1. gustos e intereses, 3.4. preferencias, 3.7. deseos, 3.9. planes e in- } \\
\text { tenciones, 3.11. estado de ánimo }\end{array}$
\end{tabular}

\subsubsection{PI 1: propuesta de mejora ${ }^{12}$}

Por un lado, ya que el apartado 3. Expresar gustos, deseos y sentimientos habla de la 'expresión', se recomendaría incluir los subapartados de 'preguntar por' (i.e., "preguntar por gustos e intereses: '¿Te gusta que te regalen flores?', nivel B1) dentro del apartado que incluye la expresión de tales emociones: 'expresar' (i.e., "expresar gustos e intereses: 'Me encanta que me llames', nivel B1) y, así, se focalizaría la atención en cómo expresamos formalmente la emoción: experimentador + verbo + estímulo.

De la misma manera, algunas emociones aparecen integradas en un mismo subapartado, como el miedo, la ansiedad y la preocupación, y podrían dividirse en tres tipos, puesto que designan emociones diferentes. Así, expresiones como 'me рreосира' о 'me da miedo', incluidas dentro de un único subapartado, pero que señalan dos emociones negativas diversas, se clasificarían separadas. En otros casos, se observa este razonamiento de división semántica, pero en expresiones opuestas (3.5. preferencia y 3.6. indiferencia o ausencia de preferencia). Sin embargo, dicha distinción no se extiende al resto de emociones, que incluyen las expresiones lingüísticas de ausencia de la emoción en cuestión dentro de una misma ${ }^{13}$ : '(no) me entusiasma / me fascina / me apasiona / me vuelve loco' (3.1. gustos e intereses).

Igualmente, llama la atención que en el título del apartado se establezca una distinción entre el gusto, el deseo y los sentimientos, puesto que, aparte de sentimientos, no solo se presentan el gusto y el deseo, sino un mayor elenco de emo-

${ }^{12}$ Las propuestas persiguen ser descriptivas, con un carácter recomendable, y no prescriptivas.

${ }^{13}$ Para que haya una coherencia en la clasificación, la "Indiferencia o ausencia de preferencia" la incluimos dentro de "Preferencia" para el análisis cuantitativo y se comenta el uso de una u otra en el estudio cualitativo. 
ciones y estados de ánimo (i.e., sensaciones físicas, nerviosismo, alegría, etc.). Así, otro de los puntos que ocasiona una doble problemática es el 3.11. Estado de ánimo (Tabla III). Este subapartado no solo presenta la función únicamente de 'preguntar', excluyendo la posibilidad de 'expresar estados de ánimo', sino que es un hiperónimo que no designa el estado de ánimo en concreto al que hace referencia. Tampoco se ha tenido en cuenta la expresión de 3.10. Planes e intenciones ni de 3.10.1. Planes e intenciones frustrados, puesto que no están relacionados con las formas lingüísticas meta (EO y ES).

Tabla III. 3.11. Preguntar por el estado de ánimo.

\begin{tabular}{|c|c|c|c|}
\hline B1 & & B2 & \\
\hline & $\begin{array}{l}\text { ¿Qué te pasa? } \\
\text { ¿Te pasa algo? } \\
\text { ¿No te pasa nada? } \\
\text { ¿Todo bien? } \\
\text { ¿(No) estás (cuantif.) enfadado...? } \\
\text { ¿No estás enfadado conmigo? } \\
\text { ¿Estás muy mal? }\end{array}$ & & $\begin{array}{l}\text { - ¿Qué te ocurre? } \\
\text { - ¿Cómo te encuentras / sientes? }\end{array}$ \\
\hline
\end{tabular}

Por último, las emociones no aparecen siguiendo un criterio de clasificación determinado y consideramos importante establecer una división según su connotación en positivas, negativas y neutras o ambiguas ${ }^{14}$. Una vez distribuidas, en la Tabla IV observamos un número relativamente proporcional entre positivas y negativas.

Tabla IV. Emociones clasificadas según connotación.

Positivas (10) Afecto / Gustos e intereses / Admiración y orgullo / Preferencia / Deseos / Alegría y satisfacción / Placer y diversión / Empatía / Alivio / Esperanza

Negativas (12) Decepción / Tristeza y aflicción / Resignación / Vergüenza / Aversión / Aburrimiento / Hartazgo / Enfado e indignación / Miedo / Ansiedad / Preocupación / Nerviosismo

Neutras (3) Sensaciones físicas / Sorpresa y extrañeza / Arrepentimiento

${ }^{14}$ Denominamos emociones neutras o ambiguas a aquellas que pueden tener una connotación positiva o negativa según la situación y contexto lingüístico: i.e., 'me sorprende que llegues ahora', 'siento haberte contestado mal'. La nueva taxonomía se ha establecido y validado adaptando la clasificación del $P C I C$ por juicio de dos expertos lingüistas. 


\subsection{PI2: ¿Qué expresiones lingüísticas aparecen en el PCIC para cada emoción y cómo se presentan por niveles (A1-B2)?}

Tras las observaciones mencionadas, nos centramos ahora en las expresiones lingüísticas (subtipos) de las emociones objeto de estudio (tipos) que servirán de referencia en el análisis de manuales (Anexo 6: Expresiones lingüísticas por emoción y nivel del $P C I C$ ). El inventario del nivel A1-A2 destaca por no incluir un gran elenco de expresiones lingüísticas, sobre todo, el nivel Acceso (A1). En este nivel inicial, el PCIC solo presenta la expresión del gusto e interés, la preferencia y el deseo -todos ellos de afectación positiva- con los verbos gustar, preferir y querer. Así, la expresión de la indiferencia o ausencia de preferencia, emoción opuesta a la preferencia no aparece en este nivel, ni se indica en el nivel Plataforma (A2). Otras de las emociones de las que no se hace mención en el nivel Plataforma son el hartazgo, la empatía, la esperanza, la decepción, la resignación, el arrepentimiento, y la vergüenza. Se trata, en su mayoría, de emociones con connotación negativa, cuya expresión lingüística no se introduce hasta el nivel Umbral (B1). Asimismo, algunas expresiones para emociones como el alivio, la sorpresa y extrañeza y la admiración y orgullo no se han considerado para el análisis, ya que no trabajaban los verbos psicológicos en cuestión (i.e., ideófonos: ‘¿Uf!').

Los niveles B1 y B2 (Umbral y Avanzado) introducen, en cambio, un abanico más amplio de los verbos meta. Al igual que en niveles inferiores, no se han considerado para el análisis aquellas expresiones que, denotando emociones, se alejaban del objetivo de este trabajo (i.e., '¡Qué rabia!', ‘Así es la vida!', etc.). Como consecuencia, emociones como la resignación y el arrepentimiento no presentan los verbos psíquicos hasta el nivel B2. En el caso de la decepción, el PCIC no recoge directamente ningún tipo de expresión en el nivel Umbral. Los subtipos de la emoción de preocupación se trabajan únicamente en los niveles Umbral y Avanzado. Las expresiones lingüísticas que la describen se analizarían cuantitativamente contabilizando cada expresión objeto de estudio y considerando aquellas cuya matriz es idéntica dentro del mismo nivel como un solo subtipo (Tabla V).

Tabla V. Expresiones lingüísticas de la preocupación consideradas para el análisis cuantitativo.

Preocupación $(n=6)$

\begin{tabular}{ll}
\hline B1 $(n=3)$ & B2 $(n=3)$ \\
Estoy preocupado $(n=1)$ & Me preocupo si $(n=1)$ \\
Me preocupa (que) (subj. presente) $(n=2)$ & Me preocupa que (subj. pasado) $(n=1)$ \\
& Me importa que (subj. pasado) $(n=1)$ \\
\hline
\end{tabular}


Así, los niveles Umbral $(n=79)$ y Avanzado $(n=159)$ incluyen una mayor variedad de expresiones en comparación a los niveles Acceso $(n=4)$ y Plataforma $(n=19)$. En el nivel B2 se presenta prácticamente el doble de expresiones que en el B1; este, a su vez, incluye 60 subtipos más que el nivel A2, que introduce 15 expresiones por encima del A1, nivel que tan solo presenta 4. Por tanto, frente al número reducido $(n=23)$ de diferentes expresiones lingüísticas que presenta el inventario de los niveles A1 y A2, el del B1 y B2 ofrece un número significativamente más elevado $(n=238)$. Del mismo modo, el número de expresiones de cada tipo de emoción según la connotación (ver Anexo 7: No de expresiones según connotación por nivel) crece a medida que el nivel de dominio aumenta, sobre todo en el paso de los niveles bajos al nivel Umbral (Gráfico 1).

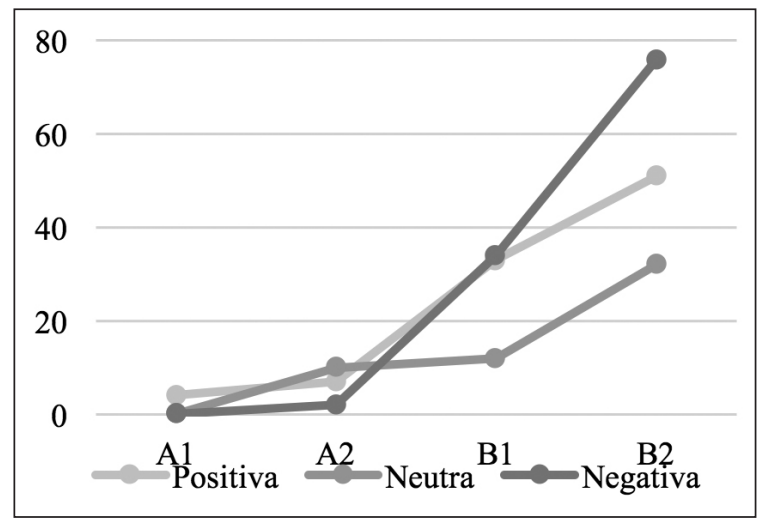

Gráfico 1. Expresiones lingüísticas según connotación entre niveles.

En el caso de las emociones positivas, en el nivel A2 se observa un aumento reducido con respecto al nivel inferior (75\%); no obstante, al pasar al nivel Umbral, la diferencia es considerablemente mayor (371,42\%), como también ocurre, incluso más extremadamente, en el paso al nivel Avanzado (545,45\%). El contraste entre el número de emociones neutras en los niveles A1 y A2 $(n=0 ; n=10$, respectivamente) con el del Umbral $(n=12)$ no resulta tan significativo como sucede en el de las emociones positivas. Llama la atención el incremento de expresiones entre niveles del mismo inventario (del A1 al A2: $n=10$; del B1 al B2: 166,66\%). En cuanto a las emociones que tienen una implicación negativa, estas quedan relegadas a los niveles más altos. Así, mientras que en el A1 no se introducen y en el A2 se incluyen tímidamente $(n=2)$, el paso al nivel Umbral marca una clara diferencia, con un total de 34 subtipos. En el último nivel analizado en el PCIC se observa un incremento del $123,52 \%$ con respecto al B1. De acuerdo con el trata- 
miento según el nivel de la lengua (Tabla VI), en el B1 estas guardan el equilibrio deseado (33 expresiones para emociones positivas y 34 para negativas), le sigue de cerca el nivel B2 (51 y 76 subtipos, respectivamente), se aleja más el A2 (7 y 2) y se llega al desequilibrio total en el nivel A1 ( 4 y 0 ).

Tabla VI. Porcentajes según connotación por nivel.

\begin{tabular}{cccc}
\hline & + & $+/-$ & - \\
\hline A1 & $4(100 \%)$ & $0(0 \%)$ & $0(0 \%)$ \\
A2 & $7(36,84 \%)$ & $10(52,63 \%)$ & $2(10,52 \%)$ \\
B1 & $33(41,77 \%)$ & $12(15,18 \%)$ & $34(43,03 \%)$ \\
B2 & $51(32,07 \%)$ & $32(20,26 \%)$ & $76(47,79 \%)$ \\
\hline
\end{tabular}

\subsubsection{PI2: propuesta de mejora}

Para el análisis cuantitativo (Anexo 8: Plantilla Excel con datos cuantitativos del $P C I C$ por emoción y nivel), no se han considerado las expresiones lingüísticas que aparecen en negativa: (no) me interesa -a no ser que estas no tengan un equivalente afirmativo: 'no soporto' / 'soporto"' o los casos en que la negación supone un cambio de emoción: 'no me importa' / 'me importa'. Por otro lado, ya que la investigación se centra en el estudio de los verbos psicológicos, se separaron aquellos subtipos que respondían a la estructura 'Experimentador-Sujeto' (ES / yo: quiero) de aquellos de construcción 'Experimentador-Objeto' (EO / me: me gustaría) (ver Anexo 6 para una división de expresiones ES y EO por emoción y nivel). De esta manera, la expresión del aburrimiento, por ejemplo, se exploró separando los subtipos como aparecen en la Tabla VII.

Tabla VII. Clasificación de expresiones según el rol semántico del Experimentador.

\begin{tabular}{ll}
\hline Aburrimiento & \\
Experimentador- Sujeto & Me aburro (B1) \\
& Me aburro de + inf. (B2) \\
Experimentador-Objeto & Me aburre (B1) \\
& Me aburre que (subj. presente) (B1) \\
& Me aburre que (subj. pasado) (B2) \\
\hline
\end{tabular}


Se contabilizaron las expresiones lingüísticas del $P C I C$ cuyas construcciones respondían a las estructuras indicadas. Igualmente, se clasificaron según su connotación y dividieron en los diferentes niveles. Esta categorización de los diferentes tipos (emociones) y subtipos (expresiones lingüísticas) sirve como punto de referencia para el posterior análisis de manuales.

En el nivel Acceso, el número de expresiones cuya cláusula codifica al experimentador como objeto es tan solo una (me gusta) frente a la presencia algo mayor de expresiones donde es sujeto, como quiero y prefiero $(n=3)$. En cambio, el nivel Plataforma no incluye ninguna expresión de este último tipo para las emociones positivas, centrándose en presentar expresiones EO como, por ejemplo, me encanta, me gustaría, me interesa $(n=7)$. En cuanto a las emociones neutras y negativas, el nivel A2 presenta un total de 9 y 2 expresiones, respectivamente, en las que el experimentador coincide con el rol sintáctico de sujeto gramatical y solo un subtipo EO (me duele) en la expresión de las sensaciones físicas. Así, antes de llegar al nivel Umbral, el PCIC establece un total de 23 expresiones lingüísticas para las distintas emociones (positivas: 11: me gusta, me encanta etc.; neutras: 10: me duele, tengo dolor...; negativas: 2: odio, no soporto). Llama la atención el número reducido de expresiones negativas y el hecho de que para emociones con esta connotación no se haya introducido todavía la cláusula EO.

El número de expresiones aumenta considerablemente en el nivel Umbral, especialmente las de estructura ES para emociones positivas y negativas (20: i.e., me divierto y 25: i.e., me preocupo, respectivamente). En emociones neutras, los subtipos en los que el experimentador es sujeto siguen siendo más comunes que en los que es objeto (9 frente a 3). En total, el número de expresiones de este último tipo es de 25 frente a más del doble en expresiones ES $(n=54)$. Finalmente, las expresiones que incorpora el PCIC para el nivel Avanzado, nivel que no se ha considerado para el análisis de manuales, ascienden a un total de 159 , siendo aquellas del tipo $\mathrm{ES}$ ( $n=90$ : i.e., me harto) relativamente más frecuentes que las EO ( $n=69$ : i.e., me divierte). Mientras que las expresiones incluidas en el $P C I C$ que denotan emociones positivas y negativas aparecen de manera muy equilibrada (positivas: 25-EO y 26-ES; negativas: 38 de cada tipo), el número de expresiones donde el experimentador es el sujeto activo para las emociones neutras se cuadriplica con respecto a aquellas de EO (26 frente a 6) (Tabla VIII). 
Tabla VIII. Expresiones ES y EO en el nivel Avanzado del PCIC.

\begin{tabular}{lll}
\hline Emoción & ES $(\boldsymbol{n}=26)$ & EO (n=6) \\
\hline $\begin{array}{l}\text { Sensaciones } \\
\text { físicas }\end{array}$ & Tengo una sed, un hambre, un frío, un calor, & Me cansa / Me agota \\
& un sueño horrible / espantoso & / Me hace daño \\
& Paso sed, hambre, frío, calor, sueño & \\
& Estoy hambriento, helado & \\
& Estoy, me siento, me encuentro cansado / & \\
& agotado & \\
& Me he hecho daño con / en & \\
& Tengo, siento un dolor horrible / espantoso & \\
& No estoy, no me encuentro nada / demasiado & \\
\hline bien & Me extraña / Me \\
extrañeza & No me lo esperaba & asombra que (subj. \\
& & pasado) \\
\hline Arrepentimiento & Siento / Lamento que (subj. pasado) & \\
\hline
\end{tabular}

Por tanto, a lo largo de los cuatro niveles analizados, el PCIC incluye más expresiones cuyo sujeto responde al rol semántico de experimentador que al de estímulo: 49 expresiones de emoción positiva (te deseo, admiro, etc.), 44 de neutra (tengo frí....) y 65 de negativa (me desespero...) en contraposición con 46 de positiva (me apetece, me entretiene, etc.), tan solo 10 de neutra (me sorprende / extraña, etc.) y 47 de negativa (i.e., me desespera).

Así, se puede observar cómo en un nivel inicial el PCIC simplemente introduce la expresión del gusto e interés mediante solo dos expresiones lingüísticas: me gusta (EO) y quiero (ES). Aparte de me gusta, el PCIC no incluye hasta el nivel Plataforma ninguna otra expresión EO. Sí presenta, aunque también tímidamente, la expresión de la preferencia (prefiero) y del deseo (quiero). La expresión del gusto, de la preferencia y del deseo aparece de nuevo tratada en el nivel Plataforma en expresiones EO como me gustaría (gusto y deseo), me encanta, me interesa y $S N$ / Infinitivo es interesante (gusto), y me gusta / interesa más (preferencia). No obstante, destaca la expresión de las sensaciones físicas y de la aversión, que aparecen por primera vez. En el caso de las sensaciones físicas, la única expresión EO es me duele, siendo el resto ES: tengo sed / hambre / frí / calor / sueño, estoy cansado / mal l enfermo, tengo dolor de. Para la aversión, las dos expresiones que presenta el PCIC en este nivel también son de este último tipo: odio, no soporto. 
Los niveles $\mathrm{B} 1$ y $\mathrm{B} 2$ presentan un elenco mucho más amplio de expresiones lingüísticas de la emoción que los niveles iniciales. En el nivel B1 se presentan por primera vez emociones positivas como el afecto, la alegría y satisfacción, el placer y diversión, la empatía, el alivio y la esperanza; emociones neutras, como la sorpresa y extrañeza; y emociones negativas, como son la tristeza y aflicción, la vergüenza, el aburrimiento, el hartazgo, el enfado e indignación, el miedo, la preocupación y el nerviosismo. Sin embargo, algunas de estas nuevas emociones positivas (i.e., la empatía, el alivio y la esperanza) no incluyen ninguna expresión ES ni EO. Se podrían haber incorporado expresiones como me tranquiliza, me da tranquilidad, me esperanza, me da esperanza. De hecho, este tipo de expresiones EO no aparecen hasta el nivel Avanzado en el caso de algunas emociones: me pone contento / de buen humor y me hace ilusión, para expresar la alegría y satisfacción; me divierte / entretiene, para el placer y diversión; me cansa, para el hartazgo; me pone nervioso / histérico y me desespera para la expresión del nerviosismo.

El nivel Avanzado, por otro lado, presenta todavía nuevas emociones, lo que desvela que, en la teoría, según los criterios de contenidos del PCIC, los alumnos de ELE no están expuestos a elementos léxicos que contengan expresiones con los verbos de afección en cuestión y que designen emociones como la admiración y orgullo, el arrepentimiento, la decepción, la resignación y la ansiedad hasta llegar al nivel B2; si bien, esto no significa que el alumno no sea capaz de expresar esas mismas emociones con otros mecanismos lingüísticos. La única de estas emociones que incluye la expresión lingüística cuya conceptualización responde a la estructura EO es la decepción: estoy decepcionado / desilusionado y me decepciona / desilusiona. Puesto que en el resto de las emociones nuevas del B2 se presentan expresiones lingüísticas que en la lengua sí tienen equivalentes de EO, se podrían haber incluido estos (i.e., me impresiona / fascina / enorgullece, para la admiración y orgullo; me agobia / inquieta, en el caso de la ansiedad).

Por otro lado, cabe resaltar algunos patrones generalizados, como, por ejemplo, el uso de expresiones EO con infinitivo o $S N$ en los niveles iniciales, con subjuntivo presente en el nivel B1 y con subjuntivo pasado en el B2 (Tabla IX). Este "reciclaje" de matrices se explica por la introducción del subjuntivo a partir del nivel Umbral $^{15}$.

${ }^{15}$ Según la $G B E$, se considera matriz a la palabra o conjunto de palabras que inducen el modo de la cláusula subordinada que les sigue. 
Tabla IX. Expresiones "recicladas" en niveles superiores al introducir el subjuntivo.

\begin{tabular}{l|l}
\hline (A1) Me gusta & (A2) Odio / No soporto \\
\hline (B1) Me gusta que (subj. presente) & (B1) Odio / No soporto que (subj. presente) \\
\hline (B2) Me gusta que (subj. pasado) & (B2) Odio / No soporto que (subj. pasado) \\
\hline
\end{tabular}

Asimismo, gran parte de las expresiones ES siguen la estructura estar + adjetivo o tener + sustantivo (estoy avergonzado / ilusionado / enfermo etc., y tengo sed / interés / miedo, etc.). También se incluyen expresiones ES y EO en las que el significado semántico ya viene integrado en el propio verbo (me avergüenzo, me decepciona, me aburro, me aburre...). Se observa, aparte, cómo a partir del nivel B1 muchas de las expresiones EO incluyen la forma a alguien (afectado) + dar (verbo de afectación) + emoción: me da miedo / igual / pena / vergüenza / asco / rabia, etc. No obstante, el PCIC no presenta una serie de expresiones cuyos correspondientes ES o EO sí introduce y que no supondría un mayor esfuerzo ni incluirlas ni, en el caso del aprendiente de ELE, aprenderlas. Véase el caso de expresiones ES, como me alegro / enamoro / impresiono y cómo el PCIC no contempla las expresiones me alegra / enamora / impresiona. De la misma manera, contempla expresiones EO (me pone furioso, me sorprende / extraña / decepciona / desilusiona / deprime) cuyos equivalentes ES no incluye. Igualmente, expresiones como me pongo triste (ES) y me pone triste (EO), no incorporan sinónimos donde el verbo contenga el significado semántico (me entristezco y me entristece).

\subsection{PI3: ¿Cómo tratan los manuales de ELE de mayor difusión la expresión de} la emoción a través de los verbos de afección? (PI3.1) ¿Se ajustan al PCIC? (PI3.2) ¿La trabajan desde un modelo de corte cognitivo y operacional?

Para el análisis de manuales hemos explorado, por un lado, el tratamiento de las emociones según su connotación y el número de expresiones de cada tipo -ES y $\mathrm{EO}-$ en los niveles A1, A2 y B1 de cada manual ${ }^{16,17}$. Con los resultados obtenidos, hemos realizado un análisis contrastivo con respecto al uso que hace de estas el

${ }^{16}$ El orden escogido para presentar el análisis de los manuales de ELE es aleatorio y simplemente responde al orden cronológico en que fueron explorados.

${ }^{17}$ En el caso de la $G B E$, la expresión de la emoción se introduce solo en el nivel A2 y B1. De ¡Genial! hemos examinado simplemente los niveles A1 y A2, ya que el nivel B1 no se había publicado en el momento del análisis. 
PCIC. Finalmente, hemos estudiado cómo se incorpora el componente cognitivo en los manuales, partiendo de la hipótesis de que probablemente se abordan las expresiones meta desde un punto de vista léxico, sin considerar la semántica. Si bien, por un lado, el manual es solo una parte de la muestra de la lengua a la que el aprendiente de ELE tiene acceso y, por otro, las guías del profesorado incorporan recomendaciones didácticas complementarias, por motivos de extensión se ha limitado el análisis a los libros de texto.

\subsubsection{Manuales analizados}

El manual Gente Hoy (A1-B1) (ver Anexo 9 como ejemplo) trata únicamente la expresión del gusto e interés y de la preferencia en el nivel A1, pero no aborda el deseo, emoción que el PCIC incluye desde el nivel Acceso. En el nivel Plataforma, se trabajan exactamente los mismos estados de afectación que se habían presentado en el nivel A1, alejándose así de las directrices del PCIC al no incluir la expresión del deseo, de las sensaciones físicas y de la aversión. De esta manera, este manual no sistematiza hasta el nivel Umbral las emociones neutras y negativas. Asimismo, este nivel introduce expresiones de la preferencia que no aparecen contempladas en el PCIC: me viene bien / mal. En cuanto al número de subtipos, en el PCIC se sigue el mismo patrón tanto en las expresiones EO como en las ES. Así, se observa un incremento a medida que el nivel aumenta (ES y EO: A1 $n=4$ / A2 $n=19$ / B1 $n=79$; EO: A1 $n=1$ / A2 $n=8$ / B1 $n=25$ ). Por otro lado, el PCIC incluye en total más subtipos que codifican el experimentador como objeto (68 frente a 34). Sin embargo, Gente incorpora significativamente más casos de expresiones lingüísticas en el nivel Acceso que en el Plataforma e introduce en total más del doble de casos de EO (346 frente a 160 de ES).

$\mathrm{Al}$ igual que el manual anterior, Campus Sur (A1-B1) trabaja desde el nivel A1 emociones como el gusto e interés y la preferencia, pero no es hasta el A2 cuando introduce el deseo. Aparte del deseo, y siguiendo las directrices del PCIC, incluye en el nivel Plataforma emociones como el gusto e interés y la emoción negativa de la aversión. Sin embargo, no menciona la preferencia o a las sensaciones físicas. Estas últimas no se tratan en ninguno de los niveles analizados. Sí presenta en el nivel A2 emociones que el PCIC se reserva hasta el nivel Avanzado como la alegría y satisfacción o el afecto y la falta de afecto -si bien estas dos ya no se vuelven a explotar en el B1-. En este último nivel del manual se trabajan tímidamente dos nuevas emociones (la envidia y la curiosidad) y se introducen expresiones - me motiva (esperanza) me estresa (nerviosismo), me tranquiliza y me relaja (alivio)que no aparecen categorizadas en el PCIC. Al igual que en el manual Gente, se presentan numerosos casos más en el nivel A1 (103) que en el A2 (26) en cuanto a las expresiones EO, y en total, estas superan con creces las construcciones de ES (226 frente a 38). 
A diferencia de los manuales previamente analizados, Bitácora (A1-B1) introduce desde el nivel A1 las emociones negativas con la expresión del nerviosismo, que el PCIC no incluye hasta el B1. En el nivel Plataforma se centra en el gusto e interés y el deseo y presenta por primera vez la preferencia, pero se aleja del PCIC al no tratar las sensaciones físicas y la aversión. Todas estas emociones las introducir nuevamente en el B1 al tratar el subjuntivo junto a otras emociones que aparecen por primera vez (el afecto, la alegría y satisfacción, la sorpresa y extrañeza, la vergüenza, el aburrimiento, y el enfado e indignación). En cuanto al número de casos, Bitácora sigue el mismo esquema que los manuales anteriores y se aleja del patrón observado en el PCIC: (ES y EO: A1 $n=89$ / A2 n=33 / B1 n=197; EO: A1 $n=80 / \mathrm{A} 2 n=31 / \mathrm{B} 1 n=155)$. Asimismo, introduce un total de casos EO significativamente más elevado (266 frente a 53 del PCIC).

En cuanto al manual Aula Internacional (A1-B1), este sigue las directrices del $P C I C$ en los niveles A1 y A2, a excepción de la aversión, cuya expresión no presenta a sus aprendientes hasta el nivel $\mathrm{B} 1$. El afecto, el placer y diversión, y emociones negativas como la vergüenza, el miedo y la preocupación se incluyen únicamente en el nivel A2, mientras que el PCIC no las considera hasta el nivel Avanzado. Del mismo modo, al margen del gusto e interés y de la admiración y orgullo (no incluidas en el PCIC hasta el $\mathrm{B} 2$ ), el manual no presenta ninguna otra emoción positiva ni neutra en el nivel $\mathrm{B} 1$ y se centra, principalmente, en las negativas. También se aleja del $P C I C$ al incluir un número más elevado de expresiones en el nivel Acceso que en el Plataforma y el Avanzado (A1n=108 / A2n=70 / B1n=93), así como de expresiones totales de EO en comparación con las de ES (210 frente a 61).

La Gramática Básica del Estudiante de español (GBE) (A2-B1), a diferencia del resto de manuales analizados, recoge únicamente los principales aspectos gramaticales del español. Las emociones no se trabajan hasta la sección 4 (Verbos), en el apartado 33 sobre indicativo y subjuntivo. Por tanto, las introduce junto con el subjuntivo en el nivel Avanzado, a excepción del deseo, que se incluye en ejercicios del A2. La GBE presenta el doble de emociones de connotación positiva que negativa y excluye las neutras (el gusto e interés, la preferencia, el deseo y la alegría y satisfacción frente a las negativas de la aversión y del enfado e indignación), que tan solo incluyen una expresión por emoción. La $G B E$ es el único manual que realmente sigue al PCIC, al incluir más casos de expresiones ES (29 frente a 13).

En el nivel Acceso, el manual Nuevo Prisma (A1-B1) tan solo incluye la expresión del gusto e interés y de las sensaciones físicas. Estas últimas las trabaja, igualmente, en el siguiente nivel junto con el resto de las emociones incluidas en el A2 por el PCIC, a excepción de la aversión. Asimismo, en el A2 se estudian nuevas emociones que no aparecen en el PCIC: la seguridad y confianza y en el Umbral, la envidia. En este último nivel, el manual incluye tímidamente la admiración y orgullo y la decepción, cuyo tratamiento en el PCIC no se presenta hasta el B2. 
Siguiendo las directrices del $P C I C$ en cuanto al número de expresiones trabajadas, Nuevo Prisma presenta un aumento proporcional (A1 $n=49$ / A2 $n=81 / \mathrm{B} 1 n=104)$. No obstante, difiere del $P C I C$ en el tratamiento significativamente mayor del total de expresiones EO (184 frente a 50).

Aunque en Etapas ( $A 1-B 1)$ se trabaja gran diversidad de emociones en el nivel A1, no se profundiza en ninguna de ellas, salvo en las sensaciones físicas. Para el nivel A2, el manual sistematiza las mismas emociones incluidas en el PCIC a excepción del deseo y la aversión. En el caso del nivel Avanzado, la expresión de las emociones negativas no se trabaja prácticamente. Al igual que Nuevo Prisma, Etapas sigue las directrices del PCIC en tanto que presenta un aumento considerable a medida que aumenta el nivel y difiere, como el manual anterior, al incluir en total casi el doble de expresiones EO (149 frente a 79 ES). Llama la atención que, en el caso de las expresiones $\mathrm{EO}$, solo haya un caso en el nivel A1: (A1 $n=1$ : me gustaría / A2n=71 / B1 $n=77)$.

Los niveles analizados (A1 y A2) del manual ¡Genial! (A1-A2) incluyen la expresión del gusto e interés y de la preferencia en ambos casos, y del deseo y las sensaciones físicas solamente en el nivel Plataforma, alejándose del PCIC en la ausencia del deseo y de la aversión en el nivel A1 y A2 respectivamente. Sin embargo, no se trabajan las emociones negativas en ninguno de los niveles. En cuanto al número de expresiones incluidas, ¡Genial! sigue el patrón observado en la mayoría de los manuales analizados: el nivel Plataforma, a diferencia de lo que indica el $P C I C$, incluye casi la mitad de casos que el nivel Acceso. Asimismo, las expresiones EO abundan a lo largo del manual (174 frente a 23).

AgenciaELE (A1-B1) sigue las directrices del PCIC en los niveles A1 y A2, a excepción de la aversión, emoción que el manual no incluye en ningún nivel. A diferencia del $P C I C$, hay una pobreza total en cuanto a la variedad de las emociones en el nivel B1, puesto que simplemente estudia el gusto e interés y el deseo, todas ellas de connotación positiva. Asimismo, difiere del PCIC en cuanto al número de expresiones que presenta en cada nivel, siendo el nivel Plataforma el que más expresiones introduce -como se ha observado en la mayoría de los manuales- y el nivel Avanzado el que menos (al igual que Aula Internacional). De la misma manera que en otros manuales, el número total de expresiones EO es considerablemente superior (204 frente a 80).

El último manual analizado, Método de español (A1-B1) presenta, al igual que Aula Internacional y AgenciaELE, coherencia con las emociones del PCIC. La única diferencia es que no hay excepciones en cuanto a no abordar una emoción en concreto. En esta línea, las sensaciones físicas, presentadas por el PCIC en el nivel Plataforma, este manual las sistematiza ya desde el nivel A1. En cuanto al B1, se presentan relativamente el mismo número de emociones que en niveles inferiores y hay un equilibrio entre el uso de emociones positivas (gustos e intereses y deseos) y las negativas (tristeza y aflicción, aversión y aburrimiento). En el caso de las ex- 
presiones lingüísticas que aparecen a lo largo del manual, Método de español invierte el patrón del PCIC, ya que el número de expresiones decrece a medida que el nivel aumenta: (A1n=341 / A2n=108 / B1n=72), patrón observado asimismo en ¡Genial! y, al igual que la mayoría incluye en total un número considerablemente mayor de EO (422 frente a 99). Tras el análisis, nos planteamos si la tendencia de algunos de estos manuales a seguir o no las recomendaciones marcadas por el PCIC podría estar relacionada con otra tendencia a la observación de unos manuales a otros.

\subsubsection{El componente cognitivo en los manuales explorados}

En cuanto al tratamiento de las estructuras meta, cabe destacar que ninguno de estos manuales las aborda explícitamente desde el principio ni parte del modelo cognitivo (Anexo 10: análisis detallado por manual). Todos responden al paradigma comunicativo clásico, que trabaja metodologías nocio-funcionales, por tareas y de acción. La excepción la presenta la $G B E$, que sigue un enfoque de acción y cognitivo, aunque no para la expresión de la emoción. Por lo general, el input gramatical se descubre inductiva y progresivamente y su explicación se limita a la sistematización de las formas verbales flexionadas en las diferentes personas gramaticales y a ejemplos.

Así, los manuales Gente, Aula Internacional, Etapas, Método y AgenciaELE presentan las cláusulas meta alejándose de la relación forma-significado y potenciando la reflexión en torno a la parte morfosintáctica de los verbos de emoción. En el caso de AgenciaELE, se habla de 'dos tipos de verbos diferentes', lo cual reduce positivamente el uso de metalenguaje, pero no se profundiza más. Campus Sur trabaja el componente cognitivo en mayor medida, al ofrecer una explicación visual con flechas y detallar que verbos como gustar, encantar o interesar provocan un efecto en alguien (el complemento indirecto), que es quien recibe la acción. Bitácora también aborda únicamente estos tres verbos, a los que denomina 'de afección', refiriéndose al sujeto no como la persona que experimenta sino como 'la cosa que produce el sentimiento'. Asimismo, potencia la reflexión lingüística al comparar estas estructuras con la lengua materna (L1) del aprendiente, lo que fomenta la resonancia emocional inherente a la L1.

Por otro lado, la $G B E$, material de apoyo para el aprendizaje autónomo, trabaja desde un enfoque cognitivo la oración subordinada (con verbo en subjuntivo), pero no la matriz léxica, la cual presenta a partir de listas de memorización, aspecto que difiere de la filosofía operativa del manual. En el caso de ¡Genial! se trabajan los verbos meta, designados como 'verbos de valoración o afección' y se explica que el sujeto es 'lo que nos gusta o valoramos'. Igualmente, se centra la atención en el contraste gusta-gustaría en términos de función, focalizando así la atención en el binomio forma-significado. No obstante, en su conjunto, en todos los manuales se 
muestran las estructuras SE y SO de manera artificiosa, ya que son reducidas a sus aspectos más formales y a taxonomías que no contemplan el porqué del hablante a la hora de utilizar una forma u otra. Al excluirse el significado gramatical, que es la base de cualquier valor pragmático y discursivo, los alumnos están expuestos a casuísticas contradictorias y contraproducentes en la evolución de su aprendizaje.

\subsubsection{Propuesta de mejora didáctica}

Para la creación de material didáctico (Anexo 11) consideramos la corrección del tratamiento de las expresiones meta y una serie de criterios comunicativo-cognitivos (Bielak y Pawlak, 2013; Alonso Raya et al., 2011; Newby, 2012) que buscan explotar significativamente el tratamiento de la expresión de la emoción, focalizando la atención en los diferentes roles que adopta el experimentador. El objetivo de esta propuesta es romper con la visión formal de la gramática presente en la mayoría de los manuales en cuanto al tratamiento de estas cláusulas. En relación con los principios cognitivos, uno de los aspectos considerados es que la secuencia se articule en torno a las cuatro fases de aprendizaje propuestas por Newby (2012): la primera, de concienciación lingüística de los alumnos hacia la forma meta; la segunda, una fase de conceptualización y formulación de hipótesis; la tercera, de procedimentalización del conocimiento lingüístico, es decir, de práctica significativa; y la última fase, basada en la actuación lingüística en tiempo real, donde el alumno incorpore los aspectos gramaticales trabajados. Igualmente, el material debe prestarse a la reflexión gramatical explícita durante las fases de presentación, realización, corrección y discusión para que este comprenda y automatice la estructura lingüística meta (expresión de la emoción) y distinga los diferentes usos de esta (cláusulas ES y EO). Es imprescindible centrar la atención en este contraste de significados para que el aprendiente interiorice la motivación semántica que subyace a la gramática y los factores pragmático-discursivos incluidos en el cambio de significado. Para ello, la explicación gramatical que presentamos ofrece una descripción consistente, unívoca y operativa del contraste entre los verbos psicológicos de ES y EO. De esta manera, el aprendiente llevará a cabo un ejercicio de reflexión cuyo resultado le permitirá asimilar la sistematicidad de los recursos gramaticales y prevenir errores potenciales.

Por otra parte, con el objeto de apoyar y facilitar la comprensión y el procesamiento de los significados gramaticales, las actividades emplean elementos figurativos y cognitivos como símbolos, colores e imágenes que ilustran el uso del valor de la forma. Este poder ilustrativo no solo ayuda al estudiante a visualizar mentalmente la intención comunicativa y la percepción del hablante, sino que lo acerca a la lengua meta y le permite establecer conexiones con su bagaje lingüístico (lengua materna y otras LEs). Esta apelación a los constructos / conceptualizaciones ya existentes en la mente del hablante para crear otras nuevas, según Arnold 
(1999), facilita la adquisición y retención a largo plazo de la forma lingüística. De la misma manera, consideramos que las analogías entre las estructuras lingüísticas y la percepción visual (Teoría de la Gestalt, también adoptada por enfoques cognitivistas) potencian la asimilación y retención de los roles que adoptan los participantes en las cláusulas de verbos de afección y, por ende, de las cláusulas problemáticas de EO.

A la integración del elemento visual hemos incorporado el factor lúdico, para así crear un ambiente de trabajo distendido en el que el alumnado viva una experiencia gramatical positiva y afectiva. Al tratarse de una secuencia centrada en la expresión de la emoción, el humor y lo lúdico cobran todavía más sentido. Por último, a la hora de diseñar la secuencia, se han tenido en cuenta aspectos como la existencia de un léxico y un metalenguaje claros y accesibles (numerosos estudios han identificado correlaciones positivas entre la conciencia metalingüística y el dominio en la LE: Sorace, 1985; White y Ranta, 2002), para que así el alumno centre su atención en el significado de la forma. No obstante, la claridad de la explicación y de los elementos que rodean a la estructura meta no implica que no haya desafío. La resolución de cada tarea debe suponer un reto y debe contemplar el error, ya que, si no hay evidencia del problema, este reincide hasta llegar a fosilizarse. Por tanto, si bien la corrección reactiva no puede abordarse explícitamente en los materiales, puesto que pertenece al momento de práctica docente, las tareas se diseñaron previendo las posibles problemáticas y previniéndolas mediante la concienciación forma-significado.

\section{RECAPITULACIÓN Y CONCLUSIONES}

La LC y en concreto la GC han experimentado grandes avances desde sus inicios en los años 80 , aunque su aplicación conceptual carece de la creación abundante de materiales de instrucción gramatical. Como hemos observado, se trata de un modelo cuyas características fundamentan teóricamente la práctica de docentes interesados en que sus alumnos extranjeros procesen y adquieran la lengua significativamente (Castañeda, 2014; Llopis García, Real Espinosa y Ruiz Campillo, 2012). Ese puente entre teoría y práctica resulta, por tanto, un requisito sine qua non para la asimilación de un área dificultosa en la adquisición de ELE, como son las cláusulas EO en verbos de afección, y para el desarrollo de una competencia comunicativa motivada en todas sus dimensiones para el alumnado. Por esta razón y partiendo de la premisa de que los principales libros de texto no trabajan suficientemente las emociones desde niveles iniciales a partir de una perspectiva cognitiva, hemos realizado un análisis de un corpus de manuales donde exploramos el inventario de emociones del PCIC y 10 de los manuales actuales de más impacto.

Tras analizar el tratamiento de la expresión de la emoción, observamos cómo 
estos manuales no se ajustan a los contenidos por niveles que propone el $P C I C$, pese a ser diseñados siguiendo las directrices del MCERL y del PCIC. Así, incorporan emociones y expresiones que el PCIC no recoge hasta niveles más avanzados, o que directamente no incluye. Algunas emociones, por el contrario, no se incluyen ni aparecen en niveles iniciales como propone el PCIC. De acuerdo con el $P C I C$, la mayoría presentan las emociones positivas en los niveles más bajos, sin incidir en las negativas hasta niveles superiores, decisión carente de lógica, puesto que esto no permite al estudiante expresarse en todo el rango emocional en niveles donde el 'yo' y lo personal son el centro de comunicación. Asimismo, aunque la gran mayoría de los manuales explorados presentan un mayor número de cláusulas EO que ES, evidenciándose así la gran frecuencia de estas construcciones 'inversas', estas no se explican atendiendo al binomio forma-significado ni considerando los roles semántico-referenciales del experimentador y del estímulo. En lo referente a la explotación de acercamientos cognitivos, no se ha encontrado ningún manual que trate todo el elenco de verbos psicológicos desde esta perspectiva.

Los resultados obtenidos son el punto de partida de investigaciones venideras en el ámbito de la didáctica de ELE, ya que sirven de base para el diseño de propuestas pedagógicas fundamentadas en una metodología cognitiva, operativa y de acción, que presenten construcciones dificultosas como las de EO partiendo de los roles de experimentador-estímulo ${ }^{18}$. En definitiva, consideramos que la LC debe seguir nutriéndose de la creación de materiales que animen al aprendiente a crear su propia narración y de estudios empíricos que potencien, por una parte, un aprendizaje más rápido y duradero del vocabulario, a la vez que una comprensión más profunda del sistema lingüístico meta; y, por otra, la mejora personal del instructor en su práctica docente.

\section{REFERENCIAS}

Alonso Raya, Rosario, Castañeda Castro, Alejandro, Martínez Gita, Pablo, Miquel López, Lourdes, Ortega Olivares, Jenaro y Ruiz Campillo, José Plácido. (2011). Gramática Básica del Estudiante de Español. A1, A2 y B1. Barcelona: Difusión.

Arnold, Jane (1999). Affect in language learning. Stuttgart: Ernst Klett Sprachen. Barcelona, Antonio y Soriano, Cristina. (2004). Metaphorical conceptualization in English and Spanish. European Journal of English Studies, 8(3), pp. 295-317. Bielak, John y Pawlak, Miroslav. (2013). Applying Cognitive Grammar in the for-

${ }^{18}$ El estudio empírico, junto al previo diseño de materiales, se está realizando así mismo como parte de mi proyecto de Tesis Doctoral. 
eign language classroom: Teaching English tense and aspect. Berlin: Springer Science \& Business Media.

Cárdenas Bernal, Francisca, Hierro Montosa, Antonio, Robles Ávila, Sara y Peláez Santamaría, Salvador. (2018a). Método de español 1. A1. Madrid: Anaya.

Cárdenas Bernal, Francisca, Hierro Montosa, Antonio, Robles Ávila, Sara y Peláez Santamaría, Salvador. (2018b). Método de español 3. B1. Madrid: Anaya.

Castañeda, Alejandro. (2014). Enseñanza de gramática avanzada de ELE: criterios y recursos. Madrid: SGEL.

Center for Open Science. (2013). Open Science Framework. Charlottesville: EU. Recuperado de https://osf.io.

CISA. (2013). Centre Interfacultaire en Sciences Affectives. Universidad de Ginebra. Recuperado de https://www.unige.ch/cisa/.

Consejo de Europa. (2002). Marco Común Europeo de referencia para las lenguas. Madrid: Secretaría General Técnica del MECD / Grupo ANAYA, S.A.

Consejo de Europa. (2004). Marco de Referencia para los Enfoques Plurales de las Lenguas y de las Culturas (MAREP). Estrasburgo: Council of Europe Publishing.

Consejo de Europa. (2017). Marco Común Europeo de referencia para las lenguas. Aprendizaje, Enseñanza, Evaluación. Volumen Companion con nuevos descriptores. Estrasburgo: Council of Europe Publishing.

Corpas, Jaime, García, Eva, Garmendia, Agustín y Sans Baulenas, Neus. (2013). Aula Internacional Nueva edición. A1 y A2. Barcelona: Difusión.

Corpas, Jaime, García, Eva, Garmendia, Agustín y Sans Baulenas, Neus. (2014). Aula Internacional Nueva edición. B1. Barcelona: Difusión.

Davies, Mark. (2002). Corpus del Español: 100 million words, 1200s-1900s. Recuperado de https://www.corpusdelespanol.org.

De Dios Martín, Isabel y Eusebio Hermina, Sonia. (2012). Etapas plus Acceso. Madrid: Edinumen.

De Dios Martín, Isabel, Menéndez, Mar y Eusebio Hermina, Sonia. (2010). Etapas plus A2.1. Madrid: Edinumen.

De Dios Martín, Isabel y Eusebio Hermina, Sonia. (2012). Etapas plus A2.2. Madrid: Edinumen.

Dewaele, Jean Marc. (2018). Pragmatic challenges in the communication of emotions in intercultural couples. Intercultural Pragmatics 15(1), pp. 29-55.

Equipo Entinema. (2009a). Etapa 2 Intercambios A1. Madrid: Edinumen. Equipo Entinema. (2009b). Etapa 3 Tópicos A2. Madrid: Edinumen. Equipo Entinema. (2009c). Etapa 4 Fotos A2. Madrid: Edinumen. Equipo Entinema. (2010a). Etapas plus A1.2. Madrid: Edinumen. Equipo Entinema. (2010b). Etapas plus B1.1. Madrid: Edinumen. Equipo Entinema. (2010c). Etapa 6 Agenda.com B1.1. Madrid: Edinumen. Equipo Entinema. (2010d). Etapa 7 Género B1.2. Madrid: Edinumen. 
Equipo Entinema. (2010e). Etapa 8 El Blog B1.3. Madrid: Edinumen. Equipo Entinema. (2010f). Etapa 9 Portafolio B1.4. Madrid: Edinumen. Equipo Nuevo Prisma. (2012). Nuevo Prisma. A1. Madrid: Edinumen. Equipo Nuevo Prisma. (2014). Nuevo Prisma. A2. Madrid: Edinumen. Equipo Nuevo Prisma. (2015). Nuevo Prisma. B1. Madrid: Edinumen. Esteba Ramos, Diana, Peláez Santamaría, Salvador, Zayas López, Purificación, Robles Ávila, Sara y Peláez Santamaría, Salvador. (2017). Método de español 2. A2. Madrid: Anaya.

Fernández, Claudia, Genta, Florencia, Lahuerta, Javier, Lerner, Ivonne, Moreno, Cristina, Ruiz, Juana, Sanmartín, Juana. (2018). Agencia ELE. B1. Madrid: SGEL-Educación.

García Sánchez, Cristina, Mena Octavio, Manuela, Méndez Santos, Ma Carmen, Tudela Capdevila, Nitzia y Cruz Moya, Olga. (2018). ¡Genial! A2. Madrid: Enclave-ELE.

Gil, Manuela, Amenós, José, Duque, Aurora, Espiñeira, Sonia, Soria, Inés, De la Torre, Nuria y Vañó, Antonio. (2017). Agencia ELE. A1 y A2. Madrid: SGELEducación.

Goldberg, Adele. (1995). Constructions: A construction grammar approach to argument structure. London: University of Chicago Press.

Grotjahn, Rüdiger. (1987). On the Methodological Basis of Introspective Methods. En C. Faerch y G. Kasper (Eds.), Introspection in Second Language Research. Clevedon Avon: Multilingual Matters, pp. 54-81.

Hartshorne, Joshua, Pogue, Amanda y Snedeker, Jesse. (2015). Love is hard to understand: The relationship between transitivity and caused events in the acquisition of emotion verbs. Journal of Child Language, 42, pp. 467-504.

Herrero Fernández, Cristina, Martínez-Delgado Veiga, María, Planelles Almeida, Margarita, Torrado Solo de Zaldívar, Pablo y Cruz Moya, Olga. (2017). ¡Genial! A1. Madrid: Enclave-ELE.

Ibarretxe Antuñano, Iraide, Cadierno-López, Teresa, Castañeda-Castro, Alejandro (Eds.) (2019). Lingüistica Cognitiva y español LE/L2. Londres: Routledge.

Instituto Cervantes. (2006). Plan curricular del Instituto Cervantes. Madrid: Biblioteca nueva. Recuperado de http://cvc.cervantes.es/ensenanza/biblioteca_ele/plan_curricular/.

Ivaz, Lela, Costa, Albert y Duñabeitia, Jon Andoni. (2016). The emotional impact of being myself: Emotions and foreign-language processing. Journal of Experimental Psychology: Learning Memory and Cognition, 42(3), pp. 489-496.

Kleinginna, Paul y Kleinginna, Anne. (1981). A categorized list of emotion definitions, with suggestions for a consensual definition. Motivation and Emotion, 5, pp. 345-379.

Kövecses, Zoltan. (2000). Metaphor and emotion: Language, culture, and body in human feeling. New York: Cambridge University Press. 
LEIDE. (2017). Lengua emoción e identidad. Alcalá de Henares. Recuperado de https://grupoleide.com.

Llopis García, Reyes. (2018). Aportaciones pedagógicas de la Lingüística Cognitiva a la enseñanza de gramática en ELE. En F. Herrera y N. Sans (Eds.), Enseñar gramática en el aula de español. Nuevas perspectivas y propuestas. Barcelona: Difusión, pp. 55-65.

Llopis García, Reyes, Real Espinosa, J.M., y Ruiz Campillo, J.P. (2012). Qué gramática aprender, qué gramática enseñar. Madrid: Edinumen.

Martín Peris, Ernesto y Sans Baulenas, Neus. (2013). Gente Hoy. A1 y A2. Barcelona: Difusión.

Martín Peris, Ernesto y Sans Baulenas, Neus. (2014). Gente Hoy. B1. Barcelona: Difusión.

Melis, Chantal. (1999). Variación sintáctica con los verbos de emoción. Español Actual, 71, pp. 49-62.

Miglio, Viola Giulia, Gries, Stefan, Harris, Michael, Wheeler, Eva y SantanaPaixão, Raquel (2013). Spanish lo (s)-le (s) clitic alternations in psych verbs: A multifactorial corpus-based analysis. Somerville: Cascadilla Press.

Molinaro, Nicola. (2020). "Words and emotions in sentence context": a commentary on Hinojosa, Moreno and Ferré (2019). Language, Cognition and Neuroscience, 35(7), pp. 862-864.

Mulligan, Kevin y Reiner Scherer, Klaus. (2012). Toward a working definition of emotion. Emotion Review, 4(4), pp. 345-357.

Newby, David. (2012). "Cognitive+Communicative grammar in teacher education”. En J. Huttner, B. Mehlmauer-Larcher, S. Reichl y B. Schiftner (Eds.), Bridging the gap: Theory and practice in EFL teacher education. Clevedon: Multilingual Matters, pp. 101-123.

Ogarkova, Anna, Soriano, Cristina y Gladkova, Anna. (2018). Methodological triangulation in the study of emotion. The case of "anger" in three language groups. En A. Píquer-Píriz y R. Alejo-González (Eds.), Applying Cognitive Linguistics. Figurative language use, constructions and typology. Amsterdam: John Benjamins, pp. 73-100.

Rosales Varo, Francisco, Moreno, Teresa, Martínez Lara, Ana, Salamanca, Pilar, Buyse, Kris, Martínez, Matilde, Murillo, Núria y Garrido, Pablo. (2017). Campus Sur. A1, A2 y B1. Barcelona: Difusión.

Ruiz Campillo, José Plácido. (2007). El concepto de no-declaración como valor del subjuntivo. Protocolo de instrucción operativa de la selección modal en español. En C. Pastor (Coord.), Actas del Programa de Formación para el profesorado de Español como Lengua Extranjera. Munich, pp. 89-146.

Sans Baulenas, Neus, Martín Peris, Ernesto, Garmendia, Agustín y Conejo, Emilia. (2018). Bitácora 1 Nueva edición. A1, A2 y B1. Barcelona: Difusión.

Sorace, Antonella. (1985). Metalinguistic knowledge and language use in acquisi- 
tion-poor environments. Applied Linguistics, 6(3), pp. 239-254.

Soriano, Cristina. (2016). El lenguaje de las emociones. En M.C. Horno Chéliz, I. Ibarretxe Antuñano y J.L Mendívil Giró (Eds.), Panorama actual de la ciencia del lenguaje. Zaragoza: Prensas de la Universidad de Zaragoza, pp. 243-259.

Talmy, Len. (2000). Toward a Cognitive Semantics. Cambridge, MA: The MIT Press.

Vázquez Rozas, Victoria. (2006). Gustar-type verbs. En J. C. Clements y J. Yoon (Eds.), Functional approaches to Spanish syntax. Lexical semantics, discourse and transitivity. Hampshire/New York: Palgrave MacMillan, pp. 80-114.

Vázquez Rozas, Victoria. (2012). Construyendo emociones: sintaxis, frecuencia y función comunicativa. En T. Jiménez, B. López Meirama, V. Vázquez Rozas y A. Veiga (Eds.), Cum corde et in nova grammatica: estudios ofrecidos a Guillermo Rojo. Santiago de Compostela: USC Editor, pp. 841-854.

Verhoeven, Elisabeth. (2007). Experiential constructions in Yucatec Maya: A typologically based analysis of a functional domain in a Mayan language (Vol. 87). Amsterdam: John Benjamins Publishing.

White, Joanna y Ranta, Leila. (2002). Examining the interface between metalinguistic task performance and oral production in a second language. Language Awareness, 11(4), pp. 259-290. 